ORIGINAL PROF-2168

\title{
ACNE VULGARIS;
}

Psychosocial stressors in patients

Dr. Naeem-Ullah Leghari, Bushra Akram, Dr. Naima Luqman

ABSTRACT...... Objective: To find out the frequency and pattern of psychosocial stressors and adverse life events in patients presenting with Acne vulgaris. Study design: A descriptive study. Place \& duration of study: The study was conducted in the Department of Psychiatry \& Behavioural Sciences, in collaboration with Dermatological Department, Nishtar Hospital, Multan from September, 2012 to November, 2012. Subjects \& Methods: The sample consisted of 50 consecutive out-patients (Female-42, Male-8) with acne. They were interviewed and The Presumptive Stressful life Events Scale (PSLES) was administered to elicit major life events and psychosocial stressors they had to face. Results were analysed from the entries in a semi structured Performa. Results: Out of 50 patients, $94 \%$ subjects reported more than one stress \& $6 \%$ reported no stress. $15(30 \%)$ were suffering from the disease 6 months to one year. We found more than one stressor. Results showed $46 \%$ of the participants reported Social Withdrawal, $40 \%$ had Academic Problems, $38 \%$ showed Frustration and Anger, 32\% had to face Critical Remarks / Stigmatization, 30\% had Low self esteem \& Negative thoughts about self, $12 \%$ presented with Suicidal Ideas / Attempts, about $22 \%$ reported disturbed Relationship with Spouse while $14 \%$ reported the Relationship problems with other family members. Conclusions: We concluded that psychosocial stressors and life events were present in significant majority of patients with acne and these emotional, social, behavioural and psychological reactions have strong association in patients suffering from acne vulgaris.

Key words: Acne, Psycho-social stressors, Life events

Article Citation:"

Leghari N, Akram B, Luqman N. Acne Vulgaris; Psychosocial stressors in patients. Professional Med J 2013;20(3): 403-408.

\section{INTRODUCTION}

Acne vulgaris (cystic acne or simple acne) is a common human skin disease, characterized by areas of skin with seborrhea (scaly red skin), comedones (blackheads and whiteheads), papules (pinheads), pustules (pimples), nodules (large papules) and possibly scarring ${ }^{1}$.

The psychosocial effect of acne was first recognized in 1948, when Sulzberger and Zaidens wrote, "There is no single disease which causes more psychic trauma and more maladjustment between parents and children, more general insecurity and feelings of inferiority and greater sums of psychic assessment than does acne vulgaris².

Acne vulgaris is a dermatosis which is most common during adolescence, when external appearance is very important, so that it can cause serious mental difficulties in young people ${ }^{3}$. According to the clinical stage, acne vulgaris is classified into three clinical forms: mild, moderate and severe forms of acne ${ }^{4}$.

Serious illness presents a crisis in people's life. Individual may suffer from severely affected relationships with family members and friends. Psychological elements may lead to negative thoughts about one's own self, the world and the situation ${ }^{5}$.

Unlike most other dermatologic diseases that may be limited to areas covered by clothing, acne vulgaris is often visible on the face. As direct consequences in young people depression and anxiety may be developed ${ }^{4}$.

Psychosocial stress is very common in people with severe acne, who may feel especially self-conscious about their skin. Severe psychosocial stressors from acne have resulted in attempted suicide ${ }^{6}$.

The psychological and social impacts of acne are a huge concern especially because it affects 
adolescents at a time they are developing their personalities ${ }^{7}$.

Mild and moderate acne could cause some severe psychological stress. At times people suffering with acne feel that their relationships with friends will be affected due to their looks. They feel uncomfortable while interacting with their friends and even their family members. They tend to withdraw themselves from people around them and do not involve themselves in any social activities. Often they tend to keep to themselves and avoid socializing when they experience an acne breakout. They tend to become solitary and avoid crowded places ${ }^{8}$.

Acne also can lead to reluctance develop social skills, fear of being mocked by others, disabling shyness, lack of concentration, impaired school performance, lower grades or missed assignments, lower performance at work, difficulty succeeding in careers due to lack of confidence, poor body image, low level of self esteem, anxiety, frustration and anger ${ }^{9}$.

The aim of the present study was to find out the frequency and pattern of psychosocial stressors and adverse life events in patients presenting with Acne vulgaris reporting to Department of Dermatology, Nishtar Hospital, Multan.

\section{MATERIAL AND METHODS}

The study was conducted jointly in the Department of Psychiatry \& Behavioural Sciences \& Department of Dermatology, Nishtar Hospital, a teaching hospital affiliated with Nishtar Medical College, Multan. Both the departments offer in-patient and out-patient treatment services.

The study included 50 consecutive out-patients (Female-42, Male-8) of Acne vulgaris in Department of Dermatology from September, 2012 to November, 2012. Females and male both were included in the study. Patients suffering from any other chronic dermatoses, eczema, xerosis, organic syndromes, chronic medical or surgical problem and those not fulfilling the criteria of the Acne vulgaris were excluded from the study. Dermatologic examination based on the clinical characteristics of the disease produced a diagnosis of acne vulgaris. Written informed consent was taken from the patients. All the information regarding demographic details was collected on the prescribed proforma and The Presumptive Stressful Life Events Scale (PSLES) ${ }^{10}$ was administered by an open ended interview to elicit major life events \& psychosocial stressors. Confidentially was also ensured.

The date was analyzed using Statistical Package for Social Sciences (SPSS) version 10.0 for frequencies and percentages. The results were depicted in the form of tables.

\section{RESULTS}

Table-I shows Demographic Characteristics of subjects. Out of 50 subjects, majority of patients $42(84 \%)$ were female, 22 (44\%) were $21-25$ years age group, $42(84 \%)$ belonged to urban area, $30(60 \%)$ single and 22(44\%) students.

Tables II shows duration of Acne. Out of 50 patients $15(30 \%)$ were suffering from 6 months to one year.

Tables III shows frequency of stressors. Out of 50 patients, 47(94\%) reported more than one stress \& $3(6 \%)$ reported no stress.

Tables IV shows list of psychosocial stressors and life events related to The Presumptive Stressful life Events Scale (PSLES). We found more than one stressor. Results showed $46 \%$ of the participants reported Social Withdrawal, 40\% had Academic Problems, 38\% showed Frustration and Anger, 32\% had to face Critical Remarks / Stigmatization, 30\% had Low self esteem \& Negative thoughts about self, $12 \%$ presented with Suicidal Ideas / Attempts, about 22\% reported 


\begin{tabular}{|c|c|}
\hline Characteristics & $\begin{array}{c}\text { Frequency } \\
\text { (Percentage) }\end{array}$ \\
\hline \multicolumn{2}{|c|}{ Sex } \\
\hline Females & $42(84 \%)$ \\
\hline Males & $8(16 \%)$ \\
\hline \multicolumn{2}{|c|}{ Age Groups } \\
\hline $16-20$ & $16(32 \%)$ \\
\hline $21-25$ & 22 (44\%) \\
\hline $26-30$ & $4(8 \%)$ \\
\hline $31-35$ & $7(14 \%)$ \\
\hline $36-40$ & $1(2 \%)$ \\
\hline \multicolumn{2}{|c|}{ Marital status } \\
\hline Single & $30(60 \%)$ \\
\hline Married & $16(32 \%)$ \\
\hline Divorced & $2(4 \%)$ \\
\hline Widow & $2(4 \%)$ \\
\hline \multicolumn{2}{|c|}{ Locality } \\
\hline Rural & $8(16 \%)$ \\
\hline Urban & $42(84 \%)$ \\
\hline \multicolumn{2}{|c|}{ Education } \\
\hline Uneducated & $8(16 \%)$ \\
\hline Primary & $4(8 \%)$ \\
\hline Middle & $4(8 \%)$ \\
\hline Matric & $10(20 \%)$ \\
\hline F.A & $5(10 \%)$ \\
\hline B.A & $8(16 \%)$ \\
\hline M.A & $8(16 \%)$ \\
\hline MBA & $3(6 \%)$ \\
\hline \multicolumn{2}{|c|}{ Occupation } \\
\hline Unemployed & $5(10 \%)$ \\
\hline Student & $22(44 \%)$ \\
\hline House wife & $13(26 \%)$ \\
\hline Employed & $8(16 \%)$ \\
\hline Farmer & $2(4 \%)$ \\
\hline \multicolumn{2}{|c|}{ Monthly Income } \\
\hline $0-5000$ & $1(2 \%)$ \\
\hline $6000-10000$ & $1(2 \%)$ \\
\hline $11000-15000$ & $5(10 \%)$ \\
\hline $16000-20000$ & $3(6 \%)$ \\
\hline
\end{tabular}

\begin{tabular}{|l|c|}
\hline \multicolumn{1}{|c|}{ Duration of Acne } & $\begin{array}{c}\text { Frequency } \\
\text { (Percentage) }\end{array}$ \\
\hline Less than 6 Months & $14(28 \%)$ \\
\hline 6 Months-I year & $15(30 \%)$ \\
\hline $2-4$ & $13(26 \%)$ \\
\hline $5-7$ & $2(4 \%)$ \\
\hline $8-10$ & $3(6 \%)$ \\
\hline $11-13$ & $2(4 \%)$ \\
\hline $20-22$ & $1(2 \%)$ \\
\hline \multicolumn{2}{|c|}{ Table-II. Duration acne } \\
\hline
\end{tabular}

\begin{tabular}{|l|c|}
\hline \multicolumn{1}{|c|}{ Stress } & $\begin{array}{c}\text { Frequency } \\
\text { (Percentage) }\end{array}$ \\
\hline Stressors reported & $47(94 \%)$ \\
\hline No stressor reported & $3(6 \%)$ \\
\hline \multicolumn{2}{|c|}{ Table-III. Frequency of stressors } \\
\hline
\end{tabular}

\begin{tabular}{|l|c|}
\hline \multicolumn{1}{|c|}{ Stressors } & Percentage \\
\hline Family and Social & $46 \%$ \\
\hline Social withdrawal & $14 \%$ \\
\hline Disturbed Relationship with Family & $12 \%$ \\
\hline Disturbed Relationship with Friends \\
\hline \multicolumn{2}{|l|}{ Marital and Sexual }
\end{tabular}

Disturbed Relationship with Spouse/Ignorance/
Involvement with others

\section{Education}

Academic Problems (Stopping Study/lgnoring

school \& college work/Not Preparation for Exam,

Lack of Concentration etc)

$40 \%$

\section{Courtship and Cohabitation}

Marriage Cancelled/Engagement break/Difficulties

in getting Marriage

$22 \%$

\section{Others}

\begin{tabular}{|l|c|}
\hline Frustration \& Anger & $38 \%$ \\
\hline Critical Remarks / Stigmatization & $32 \%$ \\
\hline Low self esteem \& Negative Thoughts about self & $30 \%$ \\
\hline Sadness / Low Mood & $22 \%$ \\
\hline Suicidal Ideas / Attempts & $12 \%$ \\
\hline Wish for Death & $8 \%$ \\
\hline
\end{tabular}

Table-IV. Psychosocial stressors/stressful life events 
disturbed Relationship with Spouse while 14\% reported the Relationship problems with other family members.

\section{DISCUSSION}

In our research, $84 \%$ were females \& $16 \%$ were males presenting with acne. This was in concordance with another research by Ikaraoha $\mathrm{Cl}$, et al., where the $65 \%$ females and $35 \%$ male ${ }^{11}$. Al-Hoqail, conducted study on $51.6 \%$ females and $48.8 \%$ male $^{12}$, however other researches reported female and male ratio respectively $71.5 \%-28.5 \%{ }^{13}, 54 \%-46 \%^{14}$ and $56 \%$ $44 \%{ }^{15}$. In this study, majority of the patients $44 \%$ were presented with acne at 21-25 years of age group. This is in accordance with Kutalic N, et al., 90 subjects from 16-21 years ${ }^{4}$ and Arbabi M, et al., 32.4\% from 20-30 years $^{16}$, Ikaraoha $\mathrm{Cl}$, et al., $100 \%$ from $18-32$ years $^{11}$ and Al-Hoqail, $100 \%$ from $15-29$ years of age group presented with acne ${ }^{12}$.

In this study, $84 \%$ belonged to urban area, $60 \%$ were single, 44\% were students \& $16 \%$ employed but lower socio-economic status. This is in accordance with various other researches reported. According to these studies $70.1 \%$ patients were from urban area ${ }^{17}, 16.9 \%$ had lower socio-economic status ${ }^{17}, 42.5 \%{ }^{16}, 54.9 \%{ }^{18}$, $49 \%{ }^{19}$ of the participants were single in various researches. One study also showed that female students with acne were significantly more depressed than male students ${ }^{20}$.

In this study, $30 \%$ of the patients were suffering from acne from 6 months to 1 year \& 28\% less than 6 months. This is in accordance with other researches. One study by Ikaraoha $\mathrm{Cl}$, et al., showed $1.7 \%$ suffering the illness one year ${ }^{11}$, Lasek RJ, et al., 38\% reported duration of illness from 1 month to 2 year $^{21}$, and Poli F, 49.6\% suffered from acne for one year ${ }^{22}$.

Present research revealed that $94 \%$ subjects reported more than one stress \& $6 \%$ reported no stress. Our findings are also interesting in light of the fact that girls are traditionally believed to pay more attention to their appearance. This is in accordance with Ikaraoha $\mathrm{Cl}$, et al., which showed $93.1 \%$ psychosocial stress of acne but 2.3\% had no stress and 4.6 Unsure ${ }^{11}$.

In present study, $46 \%$ had severe social withdrawal due to acne. This is in accordance with other researches. According to these researches, 20.7\% showed social inhibition ${ }^{11}, 64 \%$ faced embracement ${ }^{23}$, $66.7 \%$ reported avoiding social situations ${ }^{24}$ and $58.7 \%$ had social difficulties ${ }^{15}$. In a society that places great emphasis on appearance, acne sufferers often feel uncomfortable or embarrassed. A woman may be so self-conscious of her appearance that she has trouble in all social situations, not involving social activities and feeling a sense of guilt or shame, as if they are somehow responsible for their acne. These feelings can prevent a sufferer from interacting socially ${ }^{21}$.

In present study, 22\% reported relationship effect with spouse including ignorance, no romantic relationship and involvement in others, 14\% reported disturbed relationship with family and $12 \%$ with friends. It is in accordance with other studies reported. According to these studies $8.7 \%$ reported impairment in interpersonal relationship ${ }^{25}, 46.2 \%$ showed disturbed marital relationship ${ }^{12}, 23 \%$ had no romantic relationship with spouse ${ }^{6}, 23.8 \%$ showed low attachment to family ${ }^{6}, 28 \%$ had low attachment to friends ${ }^{6}, 24 \%$ had problem making friends ${ }^{23}$ and $45.6 \%$ had friendship relationship impact ${ }^{12}$.

In this study, 40\% patients reported various Academic Problems including stopping their study, ignoring school \& college work, not preparation for the exam \& lack of concentration etc. One study by Ritvo $E$, et al., showed $21 \%$ patients having academic problems ${ }^{23}$, Do $\mathrm{JE}$, et al., showed poor academic performance in $6.4 \%$ patients ${ }^{25}$ and Halvorsen JA, et al., revealed $36.8 \%$ not thriving at school ${ }^{6}$.

In this study, 20\% patient reported marriage 
cancellation, engagement break, difficulties in getting marriage due to acne. One study by Al-Hoqail, reported marriage avoidance in $56.3 \%$ acne patients $^{12}$.

In other stressors, 38\% exhibited frustration and increased anger, $32 \%$ were facing critical remarks \& stigmatization, taunting along with teasing behavior and $30 \%$ showed low self esteem including poor self-image, self-consciousness and embarrassment and negative thoughts about self. It is in accordance with other researches which that reported $71 \%$ revealed feeling of aggression and frustration ${ }^{15}, 7 \%$ showed rebellious behavior ${ }^{23}, 6 \%$ faced bullying ${ }^{6}$, $71 \%$ revealed lower self esteem ${ }^{23}$ and $58.8 \%$ loss of self-confidence ${ }^{12}$.

In this study, 22\% patients with acne had sadness \& low mood and $12 \%$ of the patient's presented with suicidal thoughts and attempts. In one study, among 16 cases of reported suicide in skin disease, 7 cases were due to acne ${ }^{26}$.

\section{LIMITATIONS \& SUGGESTIONS}

There are some limitations in this study. The sample size was small. Study subjects who had mild to moderate acne, which is most common in the adolescent population. It is possible that more severe forms of acne might demonstrate stronger correlations with psychological stress.

There are also certain suggestions. Further research with large sample size and on sever forms of acne. Psycho-education to patients is necessary for address patient's beliefs, perception and misconceptions regarding acne vulgaris. Keeping in view that, acne patients has to face lot of stressors, adequate family and social support should be emphasized in such patients.

\section{CONCLUSIONS}

We concluded that psychosocial stressors and life events were present in significant majority of patients with acne and these emotional, social behavioural and psychological reactions have strong association in patients suffering from acne vulgaris.

\section{Copyright@C 02 Feb, 2013.}

\section{REFERENCES}

1. Adityan B, Kumari R, Thappa DM. "Scoring systems in acne vulgaris". Indian J Dermatol Venereol Leprol. 2009; 75 (3): 323-6.

2. Sulzberger MB, Zaidens SH. Psychogenic factors in dermatologic disorders. Med Clin North Am. 1948; 32 : 669-72.

3. Krowchuck DP. Managing acne in adolescent. Pediatric Clin North Am. 2000; 47(4): 841-57.

4. Kurtalic N, Hadzigrahic N, Tahirovic H, Sadic S. Assessment of anxiety and depression in adolescents with acne vulgaris related to the severity of clinical features and gender. Acta Medica Academica. 2010; 39: $159-64$.

5. Maan MA, Naureen N, Saddiqua A. Anxiety, Depression and Self-Esteem among Chronic Skin Patients. A.P.M.C. 2010; 4(2): 159-65.

6. Halvorsen JA, Stern RS, Dalgard F, Thoresen M, Bjertness E, Lien L. Suicidal ideation, mental health problems, and social impairment are increased in adolescents with acne: a population-based study. J Invest Dermatol. 2011; 131(2): 363-70.

7. Adeyemi M. Acne: Psycho social impacts. Created: 2012; Updated: 2012. Retrieved from http://www.thetobagonews.com/opinion/Acne Psychosocial_impacts-167282605.html.

8. Psychological Impact of Acne Vulgaris. Online Posted on September 20, 2011. Retrieved from http://www.shopeastwest.com/blog/beauty-skincare/psychological-impact-acne-vulgaris.

9. Mulder MM, Sigurdsson V, van Zuuren EJ, Klaassen EJ, Faber JA, de Wit JB, van Vloten WA. Psychosocial impact of acne vulgaris. Evaluation of the relation between a change in clinical acne severity and psychosocial state. Dermatology. 2001;203(2):12430. 
10. Singh G, Kaur D, Kaur H. Presumptive stressful Life Events Scale for use in India. Indian J Psychiatry. 1984; 26(2):107-14.

11. Ikaraoha Cl, Taylor GOL, Anetor JI, Igwe CU, Ukaegbu QO, Nwobu GO, Mokogwu ATH. Demographic features, beliefs and socio-psychological impact of acne vulgaris among its sufferers in two towns in Nigeria. Online J Health Allied Scs. 2005; 4(1): 1-6.

12. Al-Hoqail IA. Knowledge, beliefs and perception of youth toward acne vulgaris. Saudi Med J. 2003; 24(7):765-8.

13. Tallab TM. Beliefs, perceptions and psychological impact of acne vulgaris among patients in the Assir region of Saudi Arabia. West Afr J Med. 2004; 23(1):85-7.

14. Yosipovitch G, Tang M, Dawn AG, Chen M, Goh CL, Huak Y, Seng LF. Study of Psychological Stress, Sebum Production and Acne Vulgaris in Adolescents. Acta Derm Venereol. 2007; 87(2): 135-9.

15. Hanisah A, Omar K, Shah SA. Prevalence of acne and its impact on the quality of life in school-aged adolescents in Malaysia. J Prim Health Care. 2009; 1(1): 20-5.

16. Arbabi M, Zhand N, Samadi Z, Ghaninejad H, Golestan B. Psychiatric Co-morbidity and Quality of Life in Patients with Dermatologic Diseases. Iran J Psychiatry. 2009; 4: 102-6.

17. Dogar IA, Man MA, Bajwa A, Bhatti A, Naseem S, Kausar S. Dermatological disorders;Psychiatric comorbidity. Professional Med J. 2010; 17 (2):334-49.

18. Picardi A, Amerio P, Baliva G, Barbieri C, Teofoli P, Bolli S, Salvatori V, Mazzotti E, Pasquini P, Abeni D. Recognition of depressive and anxiety disorders in

\footnotetext{
AUTHOR (S):

1. DR. NAEEM-ULLAH LEGHARI

MBBS, DPM, FCPS

Assistant Professor

Head Department of Psychiatry \& Behavioural Sciences.

Nishtar Hospital, Multan.

2. BUSHRA AKRAM

Clinical Psychologist

Department of Psychiatry \& Behavioural Sciences.

Nishtar Hospital, Multan.
}

dermatological outpatients. Acta Derm Venereol. 2004; 84(3):213-7.

19. Aslam R, Qadir A, Asad F. Psychiatric morbidity in dermatological outpatients: an issue to be recognized. J Pak Assoc Derma. Oct - Dec 2007; 17(4):235-9.

20. Kubota Y, Shirahige Y, Nakai K, Katsuura J, Moriue T, Yoneda K: Community based epidemiological study of psychosocial effects of acne in Japanese adolescents. J Dermatol. 2010; 37:617-22.

21. Lasek RJ, Chren MM. Acne vulgaris and the quality of life of adult dermatology patients. Arch Dermatol. 1998; 134 (4):454-8.

22. Poli F, Auffret N, Beylot C, Chivot M, Faure M, Moyse D, Pawin $H$, Revuz J, Dréno $B$. Acne as seen by adolescents: results of questionnaire study in 852 French individuals. Acta Derm Venereol. 2011; 91(5):531-6.

23. Ritvo E, Del Rosso JQ, Stillman MA, La Riche C. Psychosocial judgments and perceptions of adolescents with acne vulgaris: A blinded, controlled comparison of adult and peer evaluations. Biopsychosoc Med. 2011; 5(1):11.

24. Alakloby OM, Wahass SH. Quality of life in patients with chronic skin diseases. J Saudi Soc Dermatol Surgery. 2008; 12(1):26-36.

25. Do JE, Cho SM, In SI, Lim KY, Lee S, Lee ES. Psychosocial Aspects of Acne Vulgaris: A Community-based Study with Korean Adolescents. Ann Dermatol. 2009; 21(2): 125-9.

26. Cotterill JA, Cunliffe WJ. Suicide in dermatological patients and psoriasis. Br J Dermatol. 1997; 137:24650 .
Correspondence Address:

Dr. Naeem-Ullah Leghari MBBS, DPM, FCPS

Assistant Professor,

Head Department of Psychiatry \& Behavioural Sciences.

Nishtar Hospital, Multan.

naleghari@live.com
Article received on: 24/12/2012 Accepted for Publication: $\quad$ 2/102/2013 Received after proof reading: 25/03/2013 